DOI: https://doi.org/10.15688/lp.jvolsu.2019.4.1

UDC 316.74

LBC 60.56

\title{
BIOHACKING PHENOMENON IN THE CONTEXT OF ESSENTIALIST AND CONSTRUCTIVIST CONCEPTIONS OF SCIENCE ${ }^{1}$
}

\author{
Kirill A. Petrov \\ Volgograd State Medical Unoversity, Volgograd, Russian Federaton
}

\begin{abstract}
The problem of demarcation of science from non-science presupposes the existence of two principal approaches: essentialism and constructivism. Not exhausting all the variety of analytical concepts, they set the basic framework for the study of this issue for social theory. The Central principle of essentialism is the assertion of the existence of a substantial "core", which sets the unique features of science. The General position of constructivism in solving the problem of demarcation can be recognized as a denial of the existence of an invariable basis of scientific activity, science is determined by a variety of "external" factors and claimed as contingent to a variety of social phenomenas. The fundamental principle of constructivism assumes the "emptiness of science" pure space waiting for limitation and filling. The basic intuition of constructivism in relation to science is very fruitful for social theory, directing the attention of the researcher on practices associated with the reproduction of the boundaries of science / non-science, what Thomas F. Gieryn summarized in the concept of boundary-work. Depending on the cultural, economic or political context, the demarcation line is constantly redrawn. The last major clashes on the science / non-science frontier include the radical transformations of biology. It is impossible to imagine the development of biology in the second half of the twentieth century without the active use of mathematical methods and information technology. The use of open data and computer methods of working with information, coupled with open access and democratic principles of dissemination of information led not only to a change in disciplinary boundaries, but also served as an impetus for the formation of independent groups of "researchers", science enthusiasts - biohackers. Their activities, reproducing the formal principles of science, but carried out independently of the "official" science - another example of "boundary work". At the same time, neither essentialist nor constructivist theories are able to understand biohacking within their theoretical frameworks. Social research of biohackers allows to see better the basic principles of practice of building of boundary between science and nonscience and to understand the restrictions connected with application of the concept "boundary-work".

Key words: essentialism, constructivism, science, non-science, demarcation, participatory turn, biohacking.
\end{abstract}

УДК 316.74

ББК 60.56

\section{ФЕНОМЕН БИОХАКИНГА В КОНТЕКСТЕ ЭССЕНЦИАЛИСТСКИХ И КОНСТРУКТИВИСТСКИХ КОНЦЕПЦИЙ НАУКИ ${ }^{1}$}

Кирилл Алексеевич Петров

Волгоградский государственный медицинский университет, г. Волгоград, Российская Федерация

Аннотация. В теоретическом плане проблема демаркации науки от ненауки предполагает существование двух принципиальных подходов: эссенциализм и конструктивизм. Не исчерпывая все многообразие аналитических концепций, они задают базовую рамку исследования этой темы для социальной теории. Цен- 
тральным положением эссенциализма является утверждение существования субстанциального «ядра», задающего уникальные черты научной деятельности. Общим положением конструктивизма в решении проблемы демаркации можно признать отрицание неизменной основы научной деятельности, наука определяется набором «внешних» факторов и является контингентной множеству социально-культурных феноменов. Доведенный до логического предела основополагающий принцип конструктивизма предполагает «пустотность науки» - чистое пространство, ожидающее ограничения и заполнения. Эта базовая интуиция конструктивизма в отношении науки оказывается плодотворной для социальных теоретиков, направляя их внимание на практики, связанные с воспроизводством границы наука / ненаука, того, что Томас Ф. Гьерин обобщил в понятии «boundary-work»- работы по выстраиванию границы. В зависимости о культурного, экономического или политического контекстов демаркационная линия постоянно прочерчивается заново. К числу последних серьезных столкновений на границе наука / ненаука можно отнести радикальные трансформации биологии. Трудно представить развитие биологии во второй половине $\mathrm{XX}$ в. без активного применения математических методов и информационных технологий. Использование баз данных и компьютерных методов работы с информацией вкупе с открытым доступом и демократическими принципами распространения информации привело не только к изменению дисциплинарных границ, но и послужило толчком для формирования независимых групп «исследователей», энтузиастов науки, биохакеров - представителей неинституциональной, альтернативной науки, выстроенной на принципах свободного доступа к информации. Их деятельность, воспроизводящая формальные принципы научности, но осуществляемая независимо от «официальной» науки, - еще один пример работы по выстраиванию границ. В то же время ни эссенциалистская, ни конструктивистская теории не способны включить биохакинг в свои теоретические модели объяснения науки. Социальное исследование биохакеров позволяет лучше как увидеть основные принципы практик выстраивания границы между наукой и ненаукой, так и понять, в чем слабые стороны эссенциалистских и конструктивистских концепций.

Ключевые слова: эссенциализм, конструктивизм, наука, ненаука, демаркация, поворот к участию, биохакинг.

\section{Эссенциалистское решение проблемы демаркации}

Проблема демаркации прочно связана с именем Карла Поппера. В книге «Логика научного исследования» он определил ее как проблему «нахождения критерия, который дал бы нам в руки средства для выявления различия между эмпирическими науками, с одной стороны, и математикой, логикой, а также “метафизическими” системами - с другой» [Поппер 2005, 29]. Давая краткую характеристику истории этого вопроса, К. Поппер говорит, что, хотя впервые о роли индуктивного знания в науке заговорил Дэвид Юм, только Имманиул Кант сделал вопрос о разграничении научного и ненаучного знания центральным для своей философии. По этой причине К. Поппер, говоря о проблеме демаркации, называет ее «проблемой Канта». Американский социолог науки Т. Гьерин без колебаний относит К. Поппера к числу эссенциалистов, так как считает, что исследователь «отстаивает возможность и аналитическую потребность определения уникальных, необходимых и инвариантных свойств, благодаря которым возможно отграничить науку от других куль- турных практик и которыми можно объяснить необычайные достижения науки» [Gieryn 1995, 393]. Принцип фальсификации, защищаемый К. Поппером, по мнению Т. Гьерина, является жестким ядром научной деятельности. Такая характеристика попперовской модели считается дискуссионной и требует более полной экспликации.

Отвергая индуктивную логику в качестве единственного источника знания, К. Поппер критикует позитивистское решение проблемы демаркации, предполагающее выведение науки из системы высказываний, являющихся продуктом чувственного опыта. По его мнению, именно логическая процедура индукции лежит в основе принятого позитивистами требования верификации научных положений. «С моей точки зрения, - пишет К. Поппер, индукции вообще не существует. Поэтому выведение теорий из сингулярных высказываний, “верифицированных опытом” (что бы это ни означало), логически недопустимо. Следовательно, теории никогда эмпирически не верифицируемы» [Поппер 2005, 22]. Попперовская критика индукции предполагает, что эмпирическая проверка всего лишь подтверждает полученные ранее данные, но любая следую- 
щая процедура верификации может их опровергнуть. По этой причине верификация не является надежным источником получения научных сведений, но «эмпирическая система должна допускать опровержение опьтом». [Поппер 2005, 38]. Данное допущение может породить бесконечную цепь фальсификаций, которую необходимо где-то остановить.

Решение о приостановке фальсификации - это всегда соглашение. К. Поппер утверждает конвенциональность научной границы. В этом аспекте его концепция демонстрирует уязвимость для критики. Даже приняв в качестве базового критерия демаркации идею фальсифицируемости, сообщество ученых должно заключить соглашение о принципах использования фальсификации, условия которого сам К. Поппер не раскрывает. Попперовская философия науки обнаруживает собственные ограничения там, где она сталкивается с социальными аспектами решения проблемы демаркации. На этот недостаток теории фальсификации обратил внимание Гарри Коллинз [Collins 1985]. Описывая эксперименты по гравитационным волнам, он показывает, что окончательные выводы ученых о повторяемости экспериментов поставлены в зависимость от их соответствия теоретическим положениям. Для подтверждения научных данных ученым приходится использовать специфические риторические ходы, например: «человеческая ошибка», «техническая неисправность», «внешние обстоятельства» и т. д., которые, как указывает Т. Гьерин, «помогают им нейтрализовать возможные фальсифицирующие наблюдения» [Gieryn 1995, 397]. Именно риторические приемы позволяют достичь некоего соглашения, однако эта риторика не существует в нейтральной или доброжелательной среде, ученые вынуждены конкурировать, нападать и защищаться. Эссенциализм К. Поппера проистекает из его базовой установки: переместить решение проблемы демаркации в область философии и эпистемологии. В то же время идея конвенционально устанавливаемой границы открывает исследование проблемы демаркации для социальных теоретиков.

Пример социологического исследования проблемы демаркации содержится в работах американского ученого Роберта К. Мертона.
Мертоновская концепция науки очень прочно ассоциируется с исследованием этоса науки, концентрированное выражение которого зашифровано в аббревиатуре CUDOS (коммунизм, универсализм, объективность, организованный скептицизм). Наука в качестве социального института призвана производить достоверное знание, что обеспечивается существованием указанных выше норм. По замечанию Т. Гьерина, в классическом тексте Р. Мертона проблема демаркации непосредственно не обсуждается, однако составляет скрытое ядро всей проблематики исследования социальной структуры науки. Здесь следует напомнить о том, что текст «Наука и социальный порядок», написанный в 1942 г., имел цель отделить «нормальную» науку от так называемой «арийской науки», существовавшей в нацистской Германии. Описывая «аномальное» состояние науки в начале 30 -х гг. XX в., Р. Мертон говорит, что «чувство национальной и расовой чистоты превалировало на утилитарной рациональностью» [Merton 1974, 256]. Это чувство, вызывающее к жизни новый «политический код», оказывается несовместимым с научной этикой, обусловленной «функциональной необходимостью, чтобы теории или генерализации оценивались в терминах логической связанности» [Merton 1974, 258].

Это вторжение политического в область научной этики, по мысли Р. Мертона, было чем-то большим, чем простым покушением на нормальное функционирование науки. Он видит различия в способах интеграции социальных институтов. В либеральных обществах интеграция осуществляется на основе общих норм, служащих универсальными ориентирами человеческой деятельности. В то же время в диктаторских режимах она возможна вследствие «диффузного внедрения социальных стандартов» [Merton 1974, 260]. Нормы CUDOS сами по себе не могут дать реальной защиты нормальной науки от ее аномального состояния. Р. Мертон видит опасность именно в размывании границы науки как автономного социального института.

Прежде чем перейти к рассмотрению конструктивистского подхода к проблеме демаркации, необходимо подвести предварительные итоги краткого обзора основных эссенциалистских теорий. Попперовская модель 
демаркации, проблематизируя внутренние механизмы отбора научного знания, успешно показывает уникальные черты научного познания. При этом, вскрывая конвенциальный характер демаркационной линии, она оказывается неспособной объяснить социальные механизмы, лежащие в основе этого соглашения. Концепция Р. Мертона представляет собой удачное социологическое решение проблемы демаркации, однако, как и все прочие эссенциалистские концепции, она нетерпима к любым маргинальным явлениям. Мертоновская наука видится окостеневшей и застывшей, ведь любое отступление от норм CUDOS означает нарушение четкой границы.

\section{Конструктивизм Томаса Гьерина}

Все продемонстрированные недостатки эссенциалистких толкований проблемы демаркации становятся целью критики со стороны конструктивизма. Среди наиболее сильных аргументов сторонников конструктивизма демонстрация постоянной изменчивости представлений о том, что такое наука. Отсутствие консенсуса среди теоретиков в отношении границы науки также свидетельствует в пользу того, что К. Поппер, Т. Кун, Р. Мертон скорее сами конструируют границу, чем выявляют неизменную сущность науки. Проблема демаркации является частью рутинных практик не только ученых, но и администраторов, ответственных за финансирование исследований, редакторов журналов, которые «отклоняют некоторые рукописи как ненаучные» [Gieryn $1983,781]$. Ощущение стабильности научной деятельности возникает вследствие того, что каждый ученый заранее знает, что он должен делать [Gieryn 1983, 782]. Если ядром эссенциалистской программы является демонстрация уникальности научной деятельности, то внимание конструктивистов перемещается в область исследования социальных практик исследователей, журналистов, писателей, занятых прочерчиванием демаркационой линии. Их цель - получить «когнитивную власть», то есть право сделать свои определения единственно валидными и истинными представлениями о реальности.

Для анализа практик прочерчивания демаркационных линий Т. Гьерин предлагает использовать концепт «работа по выстраиванию границ» (boundary-work). Эта работа происходит тогда, когда «люди бросают вызов когнитивной власти науки, борются за обладание этой властью либо стремятся легитимировать ее, поскольку когнитивная власть обеспечивает престиж, могущество и привилегированный доступ к материальным ресурсам» [Gieryn 1995, 405]. Прагматическая, как ее называет Т. Гьерин, работа по выстраиванию границы обусловлена общественными интересами. Одни социальные группы могут стремиться к расширению когнитивной власти науки, другие - эту власть защитить либо монополизировать и узурпировать. Это описание стратегий по выстраиванию границ Т. Гьерин заканчивает вопросом: «Но что такое “наука"?» Этот вопрос имеет для Т. Гьерина не только риторическое значение. Анализ введенного Полом Старром концепта «когнитивная власть» показывает слабое место в системе аргументов конструктивистов. Смысл «когнитивной власти»-получение права устанавливать единственно легитимную систему представлений. Следовательно, к науке, по мнению конструктивистов, могут быть отнесены самые разные социальные объединения, а также связанные с ними социальные практики и эпистемологии, если они соответствовуют определению «когнитивной власти».

Понятие «когнитивная власть», сформулированное в абстрактной форме, превращается в неизменную сущность науки. Следовательно, использование этого концепта превращает конструктивистов в их оппонентов эссенциалистов. Понимая эту угрозу, Т. Гьерин пытается устранить излишнюю субстанциальность «когнитивной власти». Он доказывает, что право определять параметры реальности - это результат конкуренции. В этом положении обнаруживается своеобразная «петля»: работа по выстраиванию границ ведется различными группами или индивидами за право называться наукой, то есть обладать когнитивной властью, но право обозначать собственные представления как легитимные и возникает в процессе пограничной работы. Этот логический ход, необходимый Т. Гьерину, чтобы спасти конструктивизм от сращивания с эссенциализмом, заставляет его ут- 
верждать, что наука является ничем иным, как «пространственным “маркером” для когнитивной власти, пустым до тех пор, пока ее внутреннее не заполнится и ее границы не будут определены в контексте переговоров о том, кто и что является “научным”» [Gieryn 1995, 396].

Пустота вместо науки, пожалуй, слишком сильный образ даже для последовательного конструктивиста. Т. Гьерин меняет базовую метафору своей теории: на место пустого пространства приходит различие между картой и территорией. Он сравнивает пограничную работу с прочерчиванием линий на карте, но для этой работы не имеет значения как реально устроена территория. Работа по выстраиванию границ никак не привязана к реальным характеристикам научной «территории», важнее способы репрезентации этой борьбы в общественном сознании. Этим продиктовано обращение Т. Гьерина к идеологии, то есть к тому способу, каким работа по выстраиванию границ оказывается представленной в общественном сознании. Т. Гьерин предлагает анализ работы по выстраиванию границ науки, связанной с противостоянием биолога Джона Тиндаля когнитивной власти религии и инженерии. Этот анализ демонстрирует невозможность выявить сущность научной деятельности. Качества, навязываемые ей, возникают в контексте конкретного противостояния, вызываются уникальными практиками. Карта, которую рисует Дж. Тиндаль, не должна отражать «реального положения вещей» в науке, она должна помочь отказать религии или механике в их претензии на обладание когнитивной властью, которая может быть обменяна на «обильные материальные ресурсы и политическую мощь» [Gieryn 1983, 784].

Несомненно, к сильным сторонам конструктивизма, отстаиваемого Т. Гьерином, можно отнести признание изменчивости границы наука / ненаука, интерес к исторической детерминированности всякой новой конфигурации демаркационной линии. Наука выглядит как множество стычек между разными группами или индивидами, военной игрой за контроль над пространством, ставкой в которой является когнитивная власть. С другой стороны, наука, превращенная в пустое пространство, теряет какое-либо уникальное свойство.
Нельзя не заметить чрезвычайно уязвимое место в их концепции: работа по выстраиванию границ - это столкновение идеологий, риторических стилей. Но кого пытаются убедить противоборствующие стороны? Почему одна идеология оказывается более успешной? Каковы свойства сознания не только читателей и слушателей ученых трактатов, но и тех, кто выполняет работу по выстраиванию границ? Т. Гьерин задает этот вопрос: «Можем ли мы определить специальные социальные условия, для которых мы можем ожидать, что идеология примет ту или иную форму?» [Gieryn 1983, 783]. Но не дает ответа. Конструктивизм, начавшись как попытка дополнить эссенциалискую модель науки элементами социальной теории, в конце концов оказывается неспособным выполнить эту задачу. Он останавливается перед вопросом о социальных условиях возникновения и функционирования идеологии.

\section{«Поворот к участию» и аномальная наука}

Конструктивистский подход к решению проблемы демаркации, защищаемый Т. Гьерином, можно выразить простой формулой: «наука» - продукт работы по разграничению, конкуренции между различными группами и их идеологиями за «когнитивную власть». Социальный порядок в науке, обусловливающий ощущение того, что ученый «уже все знает», должен быть невероятным продуктом беспорядка, «военных» действий, направленных на переопределение границ. Стремление Т. Гьерина говорить о науке только как о пространстве, ожидающем ограничения и наполнения извне, объясняет его ссылки на марксистскую концепцию идеологии. Социальный порядок должен быть следствием трансляции языком социального конфликта определенного экономического порядка. Это положение является еще одним аргументом против конструктивизма, неспособного дать удовлетворительный ответ на собственную критику эссенциализма. Поиск социального объяснения проблемы демаркации заканчивается редукцией всего социального к экономическим закономерностям. Неудача конструктивистского решения должна стать импульсом к развитию в социальной теории 
объяснительных моделей, способных дать удовлетворительный ответ на вопрос демаркации научного знания. Необходимый шаг в этом направлении делает Шейла Ясанофф. Тема демаркации напрямую не обсуждается в текстах исследователя, однако значение ее идей для теоретической проработки этой проблематики сложно переоценить.

По мнению Ш. Ясанофф, своими институциональными границами современная американская академическая наука во многом обязана Вэнивару Бушу. После окончания Второй мировой войны он выпустил доклад «Наука - бесконечный фронтир». Являясь советником президента США, Буш хотел увидеть очертания науки будущего. Во время войны американская наука работала под тотальным контролем правительства в интереcax военной промышленности. «По замыслу Буша, наука должна была получить покровительство правительства и в мирное время, как это было во время войны. Однако контроль над научными предприятиями должен быть отнят у военных и передан гражданскому сообществу» [Jasanoff 2003, 227]. Идея В. Буша состояла в увеличении автономии университетской науки, не «загрязненной» промышленным применением. В. Буш установил различие между «базовой», фундаментальной и прикладной наукой. Американское правительство обещало ученым автономию и материальные ресурсы, требуя взамен «научных открытий, технологических инноваций и подготовку квалифицированного персонала» [Jasanoff 2003, 228]. Эти принципы легли в основу «общественного договора для науки в Америке».

Однако к началу 80-х гг. американское правительство попыталось пересмотреть условия этого договора, что явилось следствием аномального функционирования внутренних механизмов легитимации знания. В сентябре 1982 г. Комитет по науке, технике и общественной политике Национальной академии наук США опубликовал доклад «Научная коммуникация и национальная безопасность». Авторы этого доклада связывали рост военной силы СССР с существующей для социалистических стран возможностью использовать открытые данные научных исследований, проводимых в Америке. В ответ на этот док- лад администрация президента Рональда Рейгана предложила ужесточить контроль со стороны государства над процессами обмена научной информацией. Однако идея расширения контролирующих функций государства не вызвала одобрения у американских ученых и коллегия по научной коммуникации все той же американской Национальной академии наук выпустила свои рекомендации, предполагавшие сохранение независимости научных исследований и обмена информацией от государственного контроля. В защиту своей позиции коллегия привела четыре основных аргумента: во-первых, превосходство вооружений возможно обеспечить не методами контроля за исследователями, а через инвестиции в необходимые исследовательские программы; во-вторых, контроль сможет послужить тормозом для научных исследований; в-третьих, ни «базовая» университетская, ни «прикладная» наука не являются основными источниками информации, используемой в военной индустрии; в-четвертых, доклад коллегии «изолировал “ядро" науки различением производства продуктов научного знания от их потребления... задачей науки является создание, распространение и оценка знаний как собственной цели, но не средством материального производства» [Jasanoff 2003, 230].

Попытка правительства заключить новый общественный договор провалилась, аргументация коллегии строилась на предложенном еще В. Бушем разграничении «базовой» и «прикладной» науки. Но эта теоретическая рамка, предполагающая строгую демаркацию между «базовой» наукой и техникой, была неспособной объяснить усложнявшиеся взаимосвязи фундаментальных и прикладных исследований. «Идея науки как унитарной практики начала рушиться, когда стало ясно, что исследования варьируются от одного контекста к другому не только по дисциплинам, но, что еще более важно, с политической точки зрения - по институциональному окружению... наблюдатели начали сомневаться в том, что установленные категории фундаментальных и прикладных исследований имеют большое значение в мире, где производство и использование науки тесно связаны друг с другом, а также с более значительными социальными 
и политическими последствиями» [Jasanoff $2003,235]$. Эти вызовы в наибольшей степени касались биологии, пережившей во второй половине XX в. революционные изменения. Так, фундаментальные открытия в биологии явились продуктом увеличивающихся междисциплинарных связей биологии, кибернетики, инженерии, IT-индустрии и т. д. Плотная связка биологии и компьютерных технологий приводит к большему (по сравнению с любыми другими науками) требованию «открытости» каналов трансляции и циркуляции научных данных. Так, анализ последовательностей ДНК легче производить не в одной лаборатории, а привлекая к этой работе распределенные компьютерные сети. «Биология и биотехнологии значительно выигрывают от быстрой передачи знаний и навыков» [Jasanoff 2003, 236]. При этом требование открытости каналов передачи вызывает опасения: открытые данные могут быть использованы в коммерческих интересах промышленными компаниями или правительствами для создания новых типов вооружений.

Во второй половине XX в. граница между прикладной и фундаментальной наукой стирается, а вслед за этим размывается и граница между наукой и ненаукой, наукой и техникой. Интересы ученых оказывается сложно отличить от интересов крупных компаний. Неслучайно 80-е гг. XX в. связаны с попыткой запатентовать открытые исследователями участки цепи ДНК. Сама по себе эта идея оказалась возможной в силу того, что работа с каждым из участков, предполагала разработку уникальных технических устройств и биохимических препаратов, что делало открытый участок действительно продуктом уникальных технических и инженерных решений. Весь этот набор данных и технических устройств затрагивает интересы промышленных групп и коммерсантов, что приводит к росту финансирования исследований в биологии. Но чьи интересы отстаивают ученые? Можно ли сказать, что их деятельность служит достижению общественного блага? Независимы ли они в своих оценках новейших достижений и рисков использования новых технологий? Осознание указанных проблем приводит к возрождению требований усиления контроля над деятельностью ученых.
Доверие к науке зависит от множества факторов, среди которых отдельно следует выделить подотчетность ученых внутри профессионального сообщества. То, каким образом одни исследователи оценивают деятельность других, является элементом того самого «социального контракта науки». Важнейший механизм этой работы - обязательная процедура рецензирования (peer review). Рецензирование является не только инструментом, способным отсеять результаты научных исследований, несоответствующих базовым научным положениям, но также свидетельствует об автономии, независимости научного сообщества от контроля со стороны государственных органов. Ш. Ясанофф неоднократно повторяет, что рецензирование, или его функциональные аналоги, были механизмами управления, используемыми для легитимации как научного знания, так и автономии научного сообщества [Jasanoff 2003, 240]. В Америке уже в 80-е гг. прошлого столетия авторитет рецензирования как ключевого механизма поддержания качества научных исследований был поставлен под сомнение. При распределении средств, направляемых на проведение научных изысканий, правительство ориентировалось на решения самого профессионального сообщества. Но после печально известного «Дела Балтимора» (Baltimore affair) - предполагаемого случая «научного мошенничества в лаборатории MIT, возглавляемой нобелевским лауреатом Дэвидом Балтимором» [Jasanoff 2003, 245] - появились требования, чтобы при проведении рецензирования учитывались не только научная ценность исследования, но и все возможные социальные импликации.

Размытие границы между «базовой» и «прикладной наукой», вовлеченность исследователей в производство новых технологических устройств, привлечение научными сообществами материальных ресурсов со стороны частных компаний привело к пониманию необходимости привлечения не только ученых, специалистов к оценке проектов научных исследований и их результатов, но и непрофессионалов, что позволило бы исключить значительное количество социальных рисков. Ш. Ясанофф предлагает пересмотреть представления о структурной организации науки 
для того, чтобы сделать ее более социально ответственной. Наука, по ее мнению, должна выработать формы демократического «участия» и дискуссии, перестать «высокомерно» смотреть на неспециалистов, обратиться к технологии «смирения», практике, позволяющей учитывать мнения гражданского сообщества. Именно эту тенденцию в развитии современной науки Ш. Ясанофф называет «поворотом к участию».

\section{Биохакинг и любительская наука}

Аномальное состояние науки после разрушения общественного договора и пересмотра роли ключевого механизма поддержания социального порядка и автономии Ш. Ясанофф называет «девиантной» наукой. Ее идея практик «смирения» является проектом новой нормативной регуляции научной деятельности. Ш. Ясанофф более детально, чем Т. Гьерин, показывает, каким образом социальный контекст определяет специфику работ по выстраиванию границ. Ее идея «поворота к участию» фиксирует попытку научного сообщества преодолеть аномальное состояние, в котором оно оказалось за счет расширения собственной границы и трансформации нормативных принципов. Представляется необходимым дополнить анализ Ш. Ясанофф кратким рассмотрением уже существующих практик «участия» в науке, самым известным из которых является биохакинг.

Биохакеры - молодое движение, в основе идеологии которого лежит соединение этоса хакеров (тех самых пресловутых компьютерных «взломщиков») с огромным желанием делать науку самостоятельно. У обычных хакеров биохакеры заимствуют радикальное требование открытого, свободного доступа к научным данным и технологиям. Преимущественной областью их научных интересов является биология, поскольку именно она рассматривается как область, где применение современных компьютерных технологий и методов дает наибольшие практические результаты.

Обывателю же биохакеры известны своей активностью, мало связанной с наукой. Подобно Сергею Фаге - самому известному биохакеру из России - они стремятся использовать научные данные и на их основе изоб- рести «эликсир бессмертия», «прокачать» собственное тело и здоровье. Используя доступные лекарственные препараты с проверенной или недоказанной эффективностью, они самостоятельно разрабатывают курсы их приема, надеясь увеличить работоспособность, стать эффективнее и успешнее на рынке. В научной литературе биохакеры скорее связаны с движением «сделай-это-сам-био» (Do-It-YourselfBio). Говоря об истоках движения DIYbio, Сара Джиордано пишет: «Новая область синтетической биологии претендует на статус новой науки, основанной на обещаниях доступных лекарств и демократичной научной практики DIY. На основе геномных технологий рекомбинантной ДНК синтетическая биология использует инженерные принципы и аналогии с историей компьютерных инноваций, чтобы вдохновить новые поколения ученых как внутри, так и за пределами университетов» [Giordano 2018, 405].

Биохакеры - энтузиасты науки, они организуют собственные лаборатории, закупают или производят необходимое техническое оборудование, используя открытый доступ к научной информации, самостоятельно организуют исследования, выпускают журналы и проводят конференции. Кажется, что DIY - это альтернативная, внеинституциональная, демократическая наука. Такой романтический взгляд на биохакеров как на борцов с капитализмом и различными проявлениями патриархальной культуры, скрытой в организованной науке дискриминации, часто можно встретить у теоретиков феминизма. При этом Василис Костакис пишет, что «существуют различные типы хакеров: доброжелательный хакер в белой шляпе, который в духе (описаний. $-K$. П.) Уорка и Леви проводит эксперименты, изменяет, модифицирует, создает и / или участвует в коллективных проектах. Есть также хакер в серой шляпе, играющий неоднозначную роль. Кроме того, существует злонамеренный хакер в черной шляпе, который имеет преступные намерения, причиняет ущерб и / или крадет информацию» [Kostakis, Niaros, Giotitsas $2015,5]$. За этой скорее поэтической классификацией скрывается достаточно серьезная проблема. Несмотря на весь энтузиазм, демонстрируемый биохакерами в отношении современной науки, их технооптимизм, клю- 
чевым текстом для многих из них остается печально известный «Манифест хакера», в котором прямо утверждается, что хакер - это преступник, тот, кто сознательно идет на нарушение социальных норм. Биохакер разрушает «когнитивную власть» старых научных институтов.

В. Костакис, исследовавший функционирование hackerspaces - независимых лабораторий биохакеров, пишет, что, создавая собственное пространство, они транслируют новую систему ценностей: необходимость коллективного действия, стремление к постоянным изменениям самих себя и науки; бескорыстный интерес к инновациям, а также свободный доступ к информации и ее свободная циркуляция. Политические предпочтения биохакеров также часто становятся предметом исследования. Автор единственной на данный момент крупной работы, посвященной биохакерам, Александро Делфанти [Delfanti 2013] указывает, что их нельзя отнести к какомулибо политическому направлению. Среди биохакеров есть как сторонники левого движения, так и те, кто высказывает радикальные праволиберальные взгляды. Эта амбивалентность определяет и их отношение к экономическому порядку. Требование открытости информации может быть связанно как с идеями социального равенства и критикой биокапитализма, так и с требованием развития свободного рынка и конкуренции. Любопытный пример коллаборации биохакеров и правительства приводится в статье Сары Точетти и Сары Анжели Агуинтон [Tocchetti, Aguiton 2015]. Очевидно, что биохакеры - маргинальное научное движение, возникшее как ответ на разрушение общественного договора между наукой и обществом. Они поддерживают требование «участия» неспециалистов в деятельности науки и оценки научных достижений. Ключевой ценностью биохакинга является «открытая наука» и «открытые базы данных». Эта идея всеобщей доступности - самый важный аргумент против конструктивисткой модели науки. Предполагая, что в основе работы по выстраиванию границ лежит идея когнитивной власти - возможности единственно правильной системы представлений, конструктивизм не замечает радикальных трансформаций, связанных с практиками совместного пользования и равного доступа к научной информации [Söderberg, Delfanti 2015].

\section{Заключение}

Феномен биохакеров - это открытый вызов эссенциалистским и конструктивистским теоретическим моделям демаркации. Существование движения DIY является наилучшим свидетельством того, что наука может не быть жесткой системой, ограниченной нормами CUDOS. Именно социальный аспект науки обнажается в политической, исследовательской и экономической деятельности биохакеров. При этом их практики «участия» нарушают стройную идею сегментированного сообщества с четко распределенными функциями, защищаемую Р. Мертоном. С другой стороны, биохакеры объединяются вместе на основе достаточно внятной, хотя и не обязательно консистентной системы ценностей, что опровергает идею Т. Гьерина о «пустотности науки». Да и сама деятельность биохакеров не связана с борьбой за «когнитивную власть». Их лаборатории, журналы, конференции - не попытка присвоить когнитивную власть, но желание самостоятельно делать науку более эффективной, находясь на периферии. При этом сама идея возрастающей эффективности научных исследований, выдвигаемая биохакерами, является в большей степени продуктом неолиберальной экономической системы. В этом отношении феномен биохакинга напрямую связан с идеей распространения рыночных принципов регулирования и разрушающейся системой автономных научных институтов.

\section{ПРИМЕЧАНИЕ}

${ }^{1}$ Исследование выполнено при финансовой поддержке РФФИ в рамках научного проекта № 19001-00848 «Роль био- и нейрохакинга в системе наука-общество».

The study was conducted with the support of RFBR, project no. 19-001-00848 "The role of bio- and neurohacking in science-society system".

\section{СПИСОК ЛИТЕРАТУРЫ}

Поппер 2005 - Поппер К. Логика научного исследования. М.: Республика, 2005. 
К.А. Петров. Феномен биохакинга в контексте эссенциалистских и конструктивистских концепций науки

Collins 1985 - Collins H.M. Changing Order: Replication and Induction in Scientific Practice. L.; New Delhi: SAGE Publication, 1985.

Delfanti 2013 -Delfanti A. Biohackers. The Politics of Open Science. L.: PlutoPress, 2013.

Gieryn 1983 - Gieryn T.F. Boundary-Work and the Demarcation of Science from Non-Science: Strains and Interests in Professional Ideologies of Scientists // American Sociological Review. 1983. Vol. 48, № 6. P. 781-795.

Gieryn 1995 - Gieryn T.F. Boundaries of Science // Handbook of Science and Technology Studies. L.; New Delhi: Sage Publication, 1995. P. 393-443.

Giordano 2018 - Giordano S. New Democratic Science, Ethics, and Proper Publics // Science, Technology, \& Human Values. 2018. Vol. 43 (3). P. $401-430$.

Jasanoff 2003 - Jasanoff Sh. Technologies of Humility: Citizen Participation in Governing Science // Minerva. 2003. Vol. 41 (3). P. 223-244.

Kostakis, Niaros, Giotitsas 2015 - Kostakis V., Niaros $V$., Giotitsas Ch. Production and Governance in Hackerspaces: A Manifestation of CommonsBased Peer Production in the Physical Realm? // International Journal of Cultural Studies. 2015. Vol. 1. P. 1-19.

Merton 1974 - Merton R.K. Science and the Social Order // The Sociology of Science. Theoretical and Empirical Investigation. Chicago: The University of Chicago Press, 1974.

Tocchetti, Aguiton 2015 - Tocchetti S., Aguiton A. Is an FBI Agent a DIY Biologist Like Any Other? A Cultural Analysis of a Biosecurity Risk // Science, Technology, \& Human Values. 2015. Vol. 40 (5). P. 825-853.

Söderberg, Delfanti 2015 - Söderberg J., Delfanti A. Hacking Hacked! The Life Cycles of Digital Innovation // Science, Technology, \& Human Values. 2015. Vol. 40 (5). P. 1-6.

\section{REFERENCES}

Popper K., 2005. The Logic of Scientific Discovery. Moscow, Respublika.

Collins H.M., 1985. Changing Order: Replication and Induction in Scientific Practice. London; New Delhi, SAGE Publication.

Delfanti A., 2013. Biohackers. The Politics of Open Science. London, PlutoPress.

Gieryn T.F., 1983. Boundary-Work and the Demarcation of Science from Non-Science: Strains and Interests in Professional Ideologies of Scientists. American Sociological Review, vol. 48 , no. 6 , pp. 781-795.

Gieryn T.F., 1995. Boundaries of Science. Handbook of Science and Technology Studies. London; New Delhi, Sage Publication.

Giordano S., 2018. New Democratic Science, Ethics, and Proper Publics. Science, Technology, \& Human Values, vol. 43 (3), pp. 401-430.

Jasanoff Sh., 2003. Technologies of Humility: Citizen Participation in Governing Science. Minerva, vol. 41 (3), pp. 223-244.

Kostakis V., NiarosV., Giotitsas Ch., 2015. Production and Governance in Hackerspaces: A Manifestation of Commons-Based Peer Production in the Physical Realm? International Journal of Cultural Studies, vol. 1, pp. 1-19.

Merton R.K., 1974. Science and the Social Order. The Sociology of Science. Theoretical and Empirical Investigation. Chicago, The University of Chicago Press.

Tocchetti S., Aguiton A., 2015. Is an FBI Agent a DIY Biologist Like Any Other? A Cultural Analysis of a Biosecurity Risk. Science, Technology, \& Human Values, vol. 40 (5), pp. 825-853.

Söderberg J., Delfanti A., 2015. Hacking Hacked! The Life Cycles of Digital Innovation. Science, Technology, \& Human Values, vol. 40 (5), pp. 1-6.

\section{Information About the Author}

Kirill A. Petrov, Candidate of Sciences (Philosophy), Associate Professor, Department of Philosophy, Bioethics and Law with the Course of Sociology of Medicine, Volgograd State Medical University, Senior Researcher, Department of Ethical, Legal and Sociological Expertise in Medicine, Volgograd Medical Research Center, Pavshikh Bortsov Sq., 1, 400131 Volgograd, Russian Federation, petersoncyril@yandex.ru, https://orcid.org/0000-0002-4178-1726

\section{Информация об авторе}

Кирилл Алексеевич Петров, кандидат философских наук, доцент кафедры философии, биоэтики и права с курсом социологии медицины, Волгоградский государственный медицинский университет, старший научный сотрудник отдела этической, правовой и социологической экспертизы в медицине, Волгоградский медицинский научный центр, пл. Павших Борцов, 1, 400131 г. Волгоград, Российская Федерация, petersoncyril@yandex.ru, https://orcid.org/0000-0002-4178-1726 